\title{
Primary amenorrhea: a clinical review
}

\author{
Rupal Samal*, Syed Habeebullah
}

Department of Obstetrics and Gynecology, Mahatma Gandhi Medical College, Pondicherry, India

Received: 04 September 2017

Revised: 15 September 2017

Accepted: 29 September 2017

\section{*Correspondence:}

Dr. Rupal Samal,

E-mail: rupalsamal1 @yahoo.co.in

Copyright: ( $)$ the author(s), publisher and licensee Medip Academy. This is an open-access article distributed under the terms of the Creative Commons Attribution Non-Commercial License, which permits unrestricted non-commercial use, distribution, and reproduction in any medium, provided the original work is properly cited.

\section{ABSTRACT}

Primary amenorrhoea is a symptom with an extensive list of underlying causes, the majority of which are rare. According to the definition it should present in adolescence, although some conditions are diagnosed in childhood may present with failure of menstruation. Many causes of secondary amenorrhoea can also present with primary amenorrhoea if they arise very early in life. A systematic, compartment based approach will cover the commoner causes of primary amenorrhoea and recommend a pragmatic but cost-effective approach to achieve correct diagnosis. Treatment must be directed at the specific cause but has often wider implications for life long wellbeing like weight management, hormone replacement, sexual health and fertility.

Keywords: Gonadal dysgenesis, Hyperprolactinemia, Mullerian agenesis, Ovarian failure, Primary amenorrhea

\section{INTRODUCTION}

Amenorrhoea means absence of menstrual periods. Amenorrhoea can be of two types:

- $\quad$ Primary amenorrhea

- Secondary amenorrhea

Primary amenorhoea is defined as

- absence of menses by 14 years of age in the absence of growth or development of secondary sexual characteristics or

- absence of menses by 16 years of age regardless of the presence of normal growth and development including secondary sexual characteristics. ${ }^{1}$

Secondary amenorrhoea is defined as cessation of menstruation in a woman who had experienced menstrual bleeding previously for three normal cycles or for 6 months. ${ }^{2}$ A study in India indicated that $11.1 \%$ of adolescent girls, who presented with gynaecological complaints of menstrual disorders, had primary amenorrhea. However, the incidence of the disease in women in general is less than $1 \%{ }^{2}$

\section{PATHOPHYSIOLOGY OF MENSTRUAL BLEEDING}

The circulating oestrogen (oestradiol) levels in the body stimulate the proliferation of endometrium. Progesterone, which is produced after ovulation from the corpus luteum transforms the proliferating endometrium into secretory. If pregnancy does not occur, the secretory endometrium sheds in the form of menstrual bleeding. A complex interaction between the hypothalamic-pitutary-ovarian axis and the outflow tract (uterus, cervix and vagina) is required for the normal menstrual bleeding to take place. For a normal menstrual cycle to occur, the following are required:

- Normal functioning hypothalamus: GnRH secreted by hypothalamus

- Normal functioning pituitary glands: hormones secreted from anterior pituitary FSH, LH 
- Normal functioning ovaries: synthesis of oestrogens and progesterone. The entire spectrum of follicle development, ovulation and formation of corpus luteum occurs here

- Normal endometrial development: Endometrial lining which responds cyclically to stimulation by oestrogen and progesterone

- An intact outflow tract: Essential for normal menstrual flow. It requires a patent outflow tract and continuity of the vaginal orifice, vaginal canal and endocervix with the uterine cavity.

Any disruption in the above-mentioned departments can result in amenorrhoea. An aetiological classification can be derived based on the defects in the following 4 compartments.

- Compartment I- Disorders of the outflow tract (uterus and vagina)

- Compartment II- Disorders of the ovary

- Compartment III- Disorders of the anterior pituitary

- Compartment IV- Disorders of the CNS.

\section{COMPARTMENT I: DISORDERS OF THE OUTFLOW TRACT (UTERUS AND VAGINA)}

It includes

- Mullerian agenesis

- Imperforate hymen

- Transverse vaginal septum

- Cervical agenesis

- Androgen insensitivity syndrome

- 5 alpha reductase deficiency

- Asherman's syndrome.

\section{Mullerian agenesis}

Mayer Rokitansky Kuster Hauser (MRKH) syndrome affects 1 in every 4500 female births. Its occurrence is usually sporadic. These patients have absent uterus and vagina. But ovaries are normally well developed. Ovulation occurs normally in these girls. The karyotype is $46 \mathrm{XX}$.

The phenotype is that of a normal female with normal height and secondary sexual characteristics. External genitalia appear normal but vagina is short and blind. Exact aetiology of this condition is not known. There may be associated renal anomalies (20\%) and skeletal anomalies (12\%). ${ }^{3}$ Diagnosis is confirmed by ultrasound and karyotyping. Treatment is usually delayed until the patient is ready to start sexual activity. Most of them need vaginoplasty just before the commencement of sexual activity. Non-surgical methods like vaginal dilators have been tried in cases where there is sufficient vaginal length. Since ovulation is normal in these girls, oocytes can be retrieved and surrogacy is an option for future fertility.

\section{Imperforate hymen}

Imperforate hymen is an obstructive congenital anomaly of female genital tract. Its incidence is reported as 1 in 2000 female births. ${ }^{4}$ Girls are brought usually to emergencies with complaints of repeated episodes of cyclic abdominal pain, dysuria and rarely with acute retention of urine. On examination there is a palpable lower abdominal mass. And on genital examination there is a bluish bulging hymen (typical picture). After menarche, the blood gets collected behind the imperforate hymen resulting in haematocolpos, haematometra and haematosalpinx causing cyclic symptoms. The definitive treatment is hymenotomy or hymenectomy and commonly it is done by cruciate incision.

\section{Transverse vaginal septum}

Transverse vaginal septum (TVS) is a rare condition resulting from abnormalities in the vertical fusion between the vaginal components of the Mullerian ducts and the urogenital sinus. The septum usually varies in thickness and may be located at any level in the vagina, but most commonly found in the upper and mid-vagina. The incidence reported is 1 in 50,000-70,000 females. Clinically these girls present with cyclic lower abdominal pain and occasionally there may be a palpable lower abdominal mass. When the menstrual blood accumulates and distends structures above septum, it results in haematocolpos and haematometra. TVS is also known to be associated with imperforate anus, bicornuate uterus, coarctation of the aorta, atrial septal defect and malformation of the lumbar spine in 37-60\% affected females. Treatment of choice for these females is excision of vaginal septum. ${ }^{5}$

\section{Cervical agenesis}

According to American fertility society classification, cervical agenesis, classified as type I B Mullerian anomaly, results from abnormal fusion of the Mullerian ducts with the urogenital sinus, or atrophy of a segment of normally formed Mullerian system. The incidence of cervical agenesis is $0.01 \%$ in general population. Overall it accounts for about 3\% of all uterine anomalies. Cervical agenesis is rarely associated with a functioning uterus and presence of vagina. $4.8 \%$ of women with cervical agenesis have functioning uterus and present with hematometra. Attempts at correcting using Foley's catheter through cervical canal usually fail. After repeated attempts, it may end in hystrectomy. ${ }^{6}$

\section{Androgen insensitivity syndrome}

Androgen insensitivity syndrome is an inherited $\mathrm{X}$-linked trait with 46XY karyotype and testes producing ageappropriate normal concentrations of androgens. The main pathology is absence of cytosol receptor which is necessary for the actions of testosterone. The testes are located intraabdominally or in labia or inguinal canal. 
The testes produce testosterone and Mullerian inhibiting factor which prevents later development of Mullerian structure; so uterus is absent. Typical characteristic of AIS is evidence of feminization of the external genitalia at birth. Breast development is adequate but there is nil or scanty axillary and pubic hair at puberty. Testosterone is at normal male range. To prevent testicular malignancy, removal of the testes is done after puberty when feminization is complete or prepubertal gonadectomy along with oestrogen replacement therapy may be undertaken. Majority will have a short vagina, so vaginoplasty may be performed if necessary. It is best if the diagnosis of AIS is explained to the affected individual and family in an empathic environment with both professional and family support. ${ }^{7}$

\section{$5 \alpha$ reductase deficiency}

It is an autosomal recessive sex-limited disease with a karyotype of $46 \mathrm{XY}$. Patients classically presents with ambiguous genitalia, clitoral like phallus, bifid scrotum, pseudovaginal perineoscrotal hypospadias, and a rudimentary prostate. The uterus and fallopian tubes are absent because of normal secretion of Mullerian inhibiting substance. Testes are intact and usually are found in the inguinal canal or scrotum. Wolffian duct differentiation is normal with seminal vesicles, vasa differentia, epididymides, and ejaculatory ducts that empty into blind ending vagina.

Pubertal gynaecomastia may occur. Serum testosterone and serum oestrogen are similar to men. Parental and patient education should be done regarding the specific developmental abnormality, long term effects of gender assignment including gender identity, gender role, and sexual satisfaction. Gonadectomy should be performed to prevent or minimize virilisation. Oestrogen replacement therapy is given for inducing and maintaining feminization at the time of pubertal maturity. ${ }^{8}$

\section{COMPARTMENT II (DISORDERS OF OVARY)}

It includes

- Gonadal dysgenesis

- Pure gonadal dysgenesis

- Mixed gonadal dysgenesis

- Resistant ovary syndrome

- Premature ovarian failure

- Enzyme deficiencies: 17 a hydroxylase, aromatase

\section{Gonadal dysgenesis}

The term gonadal dysgenesis refers to a variety of diseases in which the development of the indifferent embryonic gonads to differentiated gonads is inhibited. The group includes pure gonadal dysgenesis $(46, \mathrm{XX}$ or $46, \mathrm{XY}=$ Swyer syndrome), mixed gonadal dysgenesis (mosaic 45,X0/46,XY etc.) and the Turner syndrome. ${ }^{8}$

\section{Turner syndrome}

It is the most common cause of delayed puberty and primary amenorrhoea. It occurs 1 in 2500 to 1 in 3000 live born girls. ${ }^{9}$ Karyotype of these girls is $45 \mathrm{X}$. Turner mosaics may show 46XX/45X or 46XY/45X karyotype. Mosaic Turner girls may have normal periods initially and later on present with premature ovarian failure. Classic features of Turner syndrome are short stature, web neck, cubitus valgus, low hairline, shield chest and widely placed nipples.

Associated cardiovascular abnormalities like coarctation of aorta and bicuspid aortic valves may be present. Renal abnormalities and auto immune hypothyroidism may also be associated. Karyotyping of blood is definitive in most cases. In cases of Turner syndrome with short stature, growth hormone if commenced early may increase height.

\section{Pure gonadal dysgenesis}

These individuals will be phenotypic females with streak gonads and no chromosomal abnormalities. Karyotype will be $46 X X$ or $46 X Y$. Individuals with XY karyotype should have their gonads removed. ${ }^{10}$

Swyer syndrome is associated with a mutation in the SRY gene and as a result the testes are dysgenetic and do not produce testosterone or anti Mullerian factor. The Mullerian duct persists and the patient may have rudimentary uterus and vagina. As there is a Y chromosome with dysgenetic gonads, the risk of malignant transformation is very high. So gonadectomy is the definitive treatment.

\section{Mixed gonadal dysgenesis}

Patients have streak gonad on one side and malformed testis on other side. They will have ambiguous genitalia. Mutation in SRY gene is considered as one of the aetiologies.

\section{Resistant ovary syndrome}

Resistant ovary syndrome (ROS) is a rare endocrine disorder characterized with hyper gonadotrophic hypogonadism, otherwise called Savage syndrome. They have normal female karyotype and female phenotype. There is increased plasma FSH level, but the ovary contains primordial follicles which are resistant to the action of gonadotropins. IVF using donor oocytes is the only option for ROS. ${ }^{11}$

\section{Enzyme deficiencies}

$17 \alpha$ hydroxylase deficiency and aromatase deficiency are associated with absent production of sex steroids resulting in delayed puberty. Individuals with $17 \alpha$ hydroxylase deficiency have a karyotype of 46XX or 
46XY. Uterus is absent with 46XY. Children with17 $\alpha$ hydroxylase deficiency will also have hypernatremia, hypokalaemia and hypertension due to increased mineralocorticoid production. Hence, they will need corticosteroids in addition to oestrogen and progesterone. In aromatase deficiency increased level of androgens will be there. So female child will be virilised with ambiguous genitalia resulting in primary amenorrhoea. ${ }^{8}$

\section{COMPARTMENT III (DISORDERS OF ANTERIOR PITUITARY)}

It includes Congenital disorders like Hypopituitarism and Isolated FSH deficiency.

Acquired disorders include pituitary adenomas (macroadenoma), drug induced hyper prolactinemia, hypothyroidism, empty sella syndrome.

\section{Hypopituitarism}

Congenital pan hypopituitarism will present early in childhood. They have amenorrhoea because of lack of gonadotropins. ${ }^{8}$

\section{Isolated FSH deficiency}

Isolated FSH deficiency due to a mutation in the FSH $\beta$ subunit is characterized by an extremely low serum FSH concentration. True isolated FSH deficiency presents as idiopathic hypogonadotropic hypogonadism, and is a rare cause of primary amenorrhoea. These individuals have high levels of LH and low levels of FSH and can be treated with exogenous FSH. ${ }^{12}$

\section{Hyperprolactinemia}

Hyperprolactinaemia is the commonest pituitary cause of amenorrhoea, although it is not a common presentation in adolescents with primary amenorrhoea. It is due to the development of a tumour i.e. micro $(<10 \mathrm{~mm})$ or macro $(>10 \mathrm{~mm})$ adenoma, causing overproduction of prolactin or the mass effect disrupting the tonic inhibition exerted by hypothalamic dopamine. Upto $30 \%$ may have associated galactorrhoea and only 5\% have visual field defects. Serum prolactin and pituitary imaging with MRI are more sensitive and specific in diagnosis.

Conservative approach of management is using dopamine agonist drugs. Bromocriptine is started at a dose of 1.25 mg per night for 5 nights, and is gradually titrated up to $7.5 \mathrm{mg}$ daily in two or three divided doses over about 3 weeks. Due to long term side effects Cabergoline is preferred. Carbergoline (0.25-1 mg twice-weekly up to 1 mg daily) is longer acting and better tolerated by many patients. Surgery (trans sphenoidal resection of the adenoma) is reserved for those with intolerable sideeffects to medication, non-functioning macroadenomas or suprasellar extension that has not resolved with medical therapy. ${ }^{13}$

\section{Empty Sella syndrome}

This is a benign condition arising due to congenital absence of the sellar diaphragm. It can also occur following surgery, radiotherapy or the development of a tumour. Usually manifests as hyperprolactinemia. ${ }^{13}$

\section{COMPARTMENT IV (DISORDERS OF HYPOTHALAMUS)}

It includes Congenital Kallmann syndrome, anorexia nervosa, extreme exercise, stress and obesity, excessive secretion of hormones, constitutional delay. ${ }^{13}$

\section{Congenital Kallmann syndrome}

This is a rare (1:50 000) and familial disorder, occurs due to deficient secretion of GnRH. There will be associated anosmia or hyposmia. Karyotype will be 46XX. Since their gonads are responsive to gonadotropins, ovulation can be induced with exogenous gonadotropins.

\section{Anorexia nervosa}

It is a rare cause of primary amenorrhoea. the affected individuals have a normal phenotype and sub normal secondary sexual characteristics. Treating the problem requires the cause to be addressed, which can uncover major conflicts of psychological disturbance and distorted body image in the case of eating disorders.

\section{Extreme exercise, stress}

These are functional disorders of hypothalamus pituitary axis. There is decrease in GnRH activity in hypothalamus, resulting in decrease in gonadotropins.

\section{Constitutional delay}

It is considered as a retrospective diagnosis. The individuals have a delayed maturation of HPO axis. Their bone age is also delayed. The difference of delay is not more than 1 year of chronological age. Follow up is needed to confirm the diagnosis.

\section{DIAGNOSTIC WORKUP}

When a girl with primary amenorrhoea comes, the diagnosis can be made with the aid of

- History

- Physical examination

- Imaging studies

- Hormonal evaluation

- Karyotyping

\section{History}

- Age 
- Growth chart (if available)

- Age at onset of thelarche

- Cyclic abdominal pain

- Any disorder of smell perception

- Family history

- H/o Siblings age at menarche

- Maternal age at menarche

- Neonatal/childhood encephalitis

- Inguinal/abdominal surgery

- Prior radiotherapy/chemotherapy.

\section{Physical Examination}

- Height

- Weight

- Blood Pressure

- Breast development: Tanner staging

- Pubic and axillary hair: Tanner staging

- Arm span/upper segment and lower segment ratio

- Features of Turner's syndrome

- Abdominal mass

- External genitalia

- Inguinal hernia, gonad in labia/inguinal region
- Clitoromegaly/signs of virilization

- Depth of vagina/bulging bluish membrane.

\section{Imaging studies}

- USG: Presence/absence of uterus

- HSG/SIS: Uterine synechiae

- CT/MRI: Hypothalamic/pituitary cause.

\section{Hormonal evaluation}

- $\quad$ LH, FSH

- Serum prolactin

- $\mathrm{TSH}$.

\section{Karyotyping}

- MRKH-46XX

- Turner's-45XO

- AIS-46XY

- Gonadal dysgenesis-46XX, 46XY .

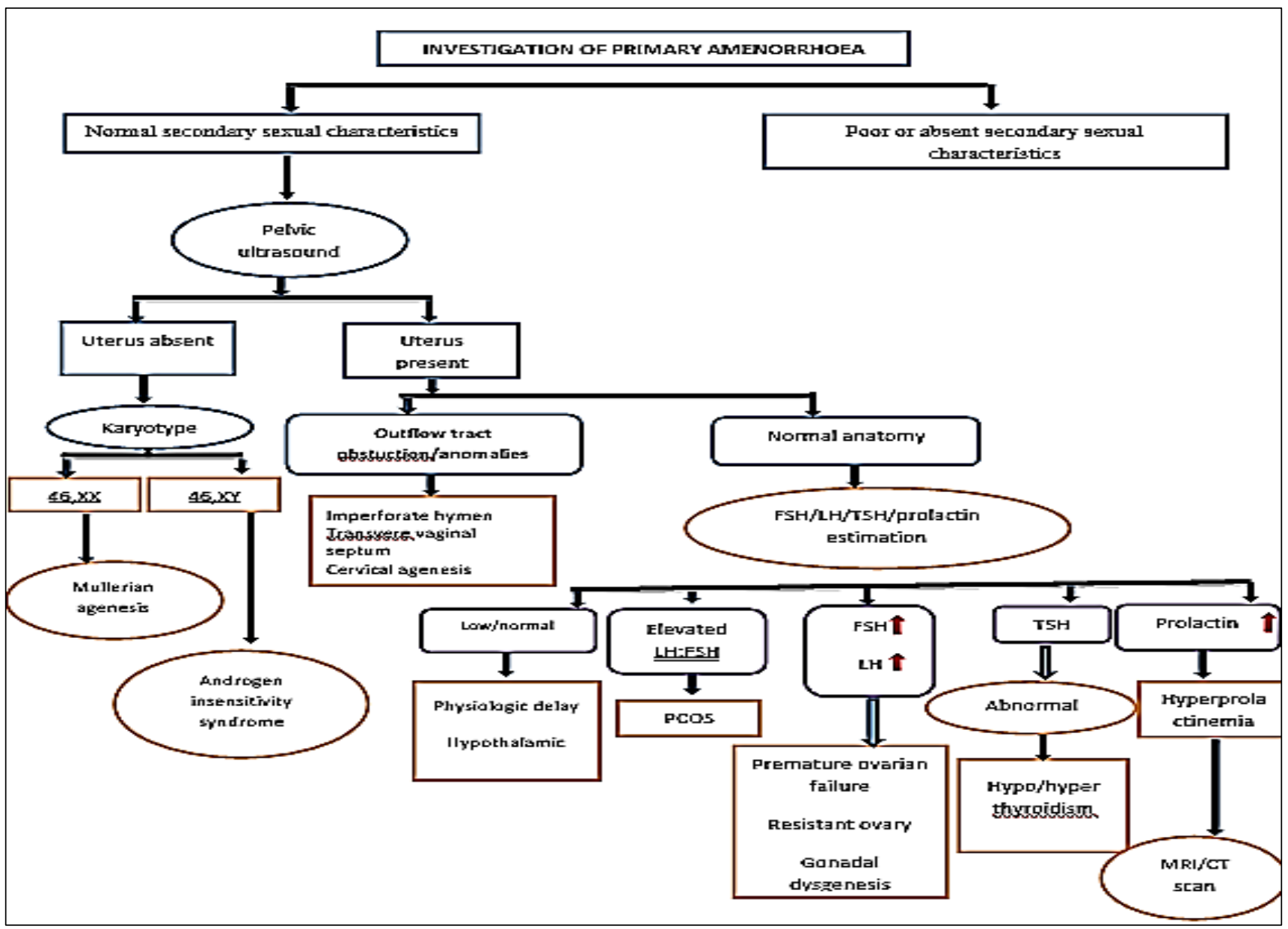

Figure 1: Investigation of primary amenorrhoea. 


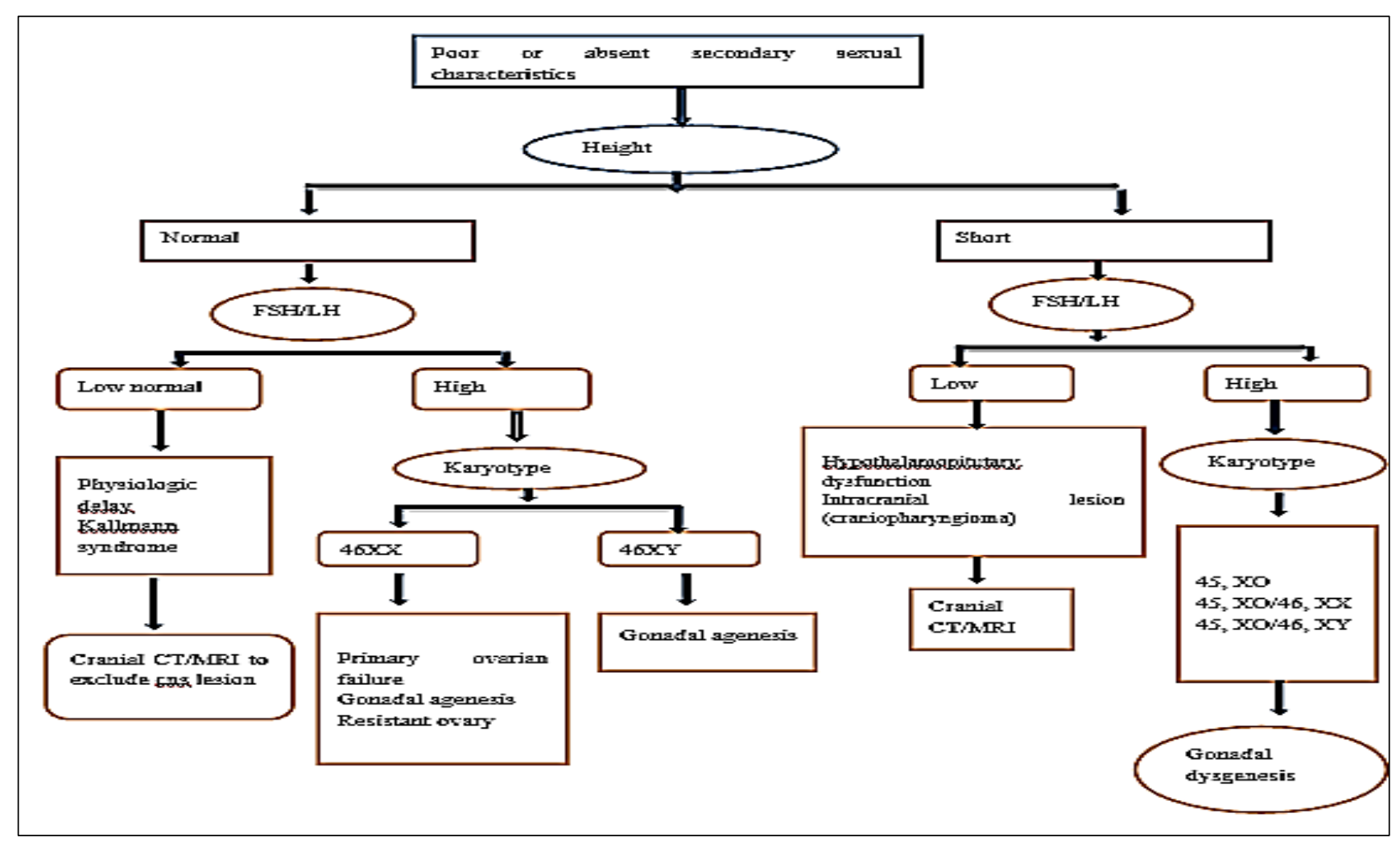

Figure 2: Poor or absent secondary sexual characteristics.

Funding: No funding sources

Conflict of interest: None declared

Ethical approval: Not required

\section{REFERENCES}

1. Marc AF, Speroff L. Amenorrhoea. Clinical Gynecologic Endocrinology And Infertility. $9^{\text {th }}$ ed. Philadelphia: Wolter Kluwer (Replica Press); 2015:43593.

2. Reeja T, Sunil S. Primary amenorrhoea. Available at http://www.medindia.net. Accessed on 3April 2008.

3. Guerrier D, Mouchel T, Pasquier L, Pellerin I. The Mayer-Rokitansky-Küster-Hauser syndrome (congenital absence of uterus and vagina)-phenotypic manifestations andgenetic approaches. J Negative Results in Bio Med. 2006;5:1.

4. Temizkan O, Kucur SK, Ağar S, Gözükara İ, Akyol A, Davas İ. Virginity sparing surgery for imperforate hymen. J Turkish-German Gynecol Assoc. 2012;13:278-80.

5. Opoku BK, Kwarteng RO, Prempeh PA. Transverse vaginal septum with menouria and unilateral renal agenesis-case report. Gynecol. 2015;3:1.

6. Helmy YA. Cervical agenesis with a functioning uterus: successful surgical treatment by Foley's catheter stent: a case report. Middle East Fertility Society J. 2017;22(1):67-9.
7. Gottlieb B, Beitel LK, Trifiro MA. Androgen insensitivity syndrome. 1999 mar 24. In: Pagon RA, Adam MP, Ardinger HH. editors. Gene Reviews®. Seattle (WA): University of Washington, Seattle; 2017:20301602. Available https://www.ncbi.nlm.nih.gov/books/NBK1429

8. Presannakumari B. Primary Amenorrhoea. Postgraduate Gynaecology. $1^{\text {st }}$ ed. New Delhi:Jaypee Brothers; 2011:55-80.

9. Virginia PS, Elizabeth MC. Turner's Syndrome. N Engl J Med. 2004;351:1227-38.

10. Leigh B. Gonadal dysgenesis Gynakol Geburtsmed Gynakol Endokrinol. 2009;5(2):82-94.

11. Li Y, Pan P, Yuan P, Qiu Q and Yang D. Successful live birth in a woman with resistant ovary syndrome following in vitro maturation of oocytes. J Ovarian Research. 2016;9:54.

12. Krishnan A, Murdock C, Allard J, Cisar M, Reid E, Nieman L, et al. Pseudo-isolated FSH deficiency caused by an inhibin B-secreting granulosa cell tumour: Case report. Human Reprod. 2003:18;502-5.

13. Catherine HJ, Adam BH. Primary amenorrhoea: investigation and treatment. Obstet Gynecol Reprode Med. 2007;17:7:200-4.

Cite this article as: Samal R, Habeebullah S. Primary amenorrhea: a clinical review. Int J Reprod Contracept Obstet Gynecol 2017;6:4748-53. 